\title{
Psychiatric Health Problems and Health Seeking Behavior of Men Who Have Sex with Men (MSM) in Agra city, Uttar Pradesh \\ Khan Iqbal Aqeel ${ }^{1}$, S.S. Chaudhary ${ }^{2}$, Geetu Singh ${ }^{1}$, S.K. Misra ${ }^{3}$ \\ ${ }^{1}$ Assistant Professor, ${ }^{2}$ Associate Professor, ${ }^{3}$ Professor and Head, Department of Social and Preventive Medicine, Sarojini Naidu Medical College, Agra, Uttar Pradesh, India \\ Correspondence : Dr. Khan Iqbal Aqeel, Email: uniqueiqbalsnmc@gmail.com
}

\section{Abstract:}

Introduction: Researches had shown that Men who have Sex with Men (MSM) have higher chances of having psychiatric disorder as compared to heterosexual men. Ongoing homophobia, stigma and discrimination have negative effects on mental health of MSM. Many MSM do not seek care from mental health provider because of fear of discrimination Objectives: This study was carried out to assess psychiatric health problem among MSM and also assess their health seeking behavior. Method: The Snowball sampling technique was used. First participants were recruited through a non-profit peer group. Further participants were subsequently referred by participants from their peer circles. Data obtained from total 52 MSM using pretested questionnaire and General health questionnaire (GHQ-28) was analyzed using MS Excel. Results: Two-fifth (40.38\%) of MSM had self-reported psychiatric health problem. While on GHQ, 57.69\% of MSM were found to have psychiatric health problem with GHQ score of $\geq 24$. MSM who were completely homosexual and who were victims/doer of violence with sex partners had significantly higher chances of having psychiatric health problem.57.15\% MSM sought treatment for their psychiatric problem from an Allopathic doctor. Rest of them either went for a self treatment (28.57\%) or not taken any treatment (14.28\%). 75\% MSM reportedly sought treatment from private health facility. Better facility, cost effectiveness, someone known recommended were most commonly cited reason for preferring a mental health provider. Conclusion: High prevalence of psychiatric health problems was found among MSM who engage in higher-risk sexual behavior. MSM require access to mental health screening services.

Key words : Health seeking behavior, Mental health, Men who have sex with men, Psychiatric health problem

\section{Introduction:}

Mental Health of Men who have sex with men (MSM) has received increased attention in recent years. ${ }^{[1,2]}$ MSM experience significant mental health disparities, including depression, anxiety, distress and trauma.$^{[3-6]}$ As compared with heterosexual men, rates of depression and distress are estimated to be $17 \%$ higher among $\mathrm{MSM}^{[7]}$ and rates of posttraumatic stress disorder (PTSD) is twice among

\begin{tabular}{|c|l|}
\hline Quick Response Code & Access this article online \\
\hline & Website : \\
& www.healthlinejournal.org \\
\cline { 2 - 2 } & DOI : \\
& $10.51957 /$ Healthline_241_2021
\end{tabular}

MSM compared with heterosexual men. ${ }^{[8,9]}$ Meyer's sexual minority stress model was the first to specifically posit that mental health problems in LGBT populations arise from minority stress. ${ }^{[8,9]}$ Accordingly, mental health problems are consequences of distressing environments, including stigma, prejudice and discrimination, which result in negative psychological outcomes including expectations of rejection, hiding and concealing,

\section{How to cite this article :}

Khan IA, Chaudhary SS, Misra SK. Psychiatric health problems and health seeking behavior of men who have sex with men (MSM) in Agra city, Uttar Pradesh. Healthline. 2021;12(3):45-51. 
internalised homophobia or homonegativity and problematic coping strategies. Psychiatric health issues may thus contribute to the propensity for MSM to engage in risky sexual behavior and may affect the degree to which they might benefit from STD and HIV prevention programs. ${ }^{[10-13]}$ The gross stigmatization of homosexuality and discrimination has affected their psychiatric health seeking behavior. With this background, the present study was conducted to assess the psychiatric health problems and healthseeking behavior among MSM residing in Agra city of Uttar Pradesh.

\section{Method:}

This descriptive observational study was conducted among MSM population residing in Agra district of Uttar Pradesh, India between August 2018 and January 2020. The inclusion criteria for the participants of the study were: 1)Self reported samesex sexual orientation in last 1 year; and 2) 18 years or older at the time of interview. Participants were recruited through the snowball sampling technique. The first participant was recruited through a nonprofit peer group. Further participants were subsequently referred by the participants from their peer circles. The exclusion criteria included: 1) Self reported HIV positive status since experience of HIV diagnosis increases guilt and other psychiatric issues associated with their sexual behavior. This has a propensity to create bias in the interviews. Also, HIV positive individuals (especially recently diagnosed) have special psychosexual and mental health needs from general MSM people. 2) Critically ill or suffering from end stage disease; 3) Lack of willingness to participate in the study. Data collection was done from September 2018 to November 2019. A total of 52 MSM participated in the study. The proforma schedule used for quantitative assessment were pretested, predesigned and structured. A mixed questionnaire was used in the study where closed ended questions were asked to assess their sexual practices and health seeking behaviour and open ended question was kept to explore self-reported psychiatric illness and the reasons for prefering a health care facility. Before start of the interview, the participants were explained about the purpose of the study and sensitive nature of the questionnaire. Informed consent was taken and confidentiality was assured. Also, Goldberg 28 point's general health questionnaire (GHQ) ${ }^{[14]}$ used as self reporting screening procedure to detect respondents suffering from psychiatric illness. Psychiatric morbidity likely to be present if GHQ threshold score is above 24 out of a maximum possible score of 84.GHQ score if found to be less than 24 than it translates to absence of any psychiatric health problem among them. Information collected on the study schedule was transferred on pre-designed classified tables and analyzed according to the aims and objectives and represented by tables analysed through MS excel. Ethical clearance for the study was taken from the Institutional Ethical Clearance Committee, Sarojini Naidu Medical College and Hospital, Agra.

Results:

Self-reported psychiatric health problems: When asked about the occurrence of any psychiatric health problems during the past 1 year, $40.38 \%$ of MSMhad

Table 1: Distribution of respondents by self reported presence of any Psychiatric health problems in past one year $(\mathrm{N}=52)$

\begin{tabular}{|c|c|}
\hline $\begin{array}{c}\text { Self-reported } \\
\text { Psychiatric health } \\
\text { problems } \\
\text { in past one year }\end{array}$ & $\begin{array}{c}\text { Number of } \\
\text { respondents } \\
\text { n (\%) }\end{array}$ \\
\hline Present & $21(40.38 \%)$ \\
\hline Absent & $31(59.61 \%)$ \\
\hline Total & $52(100 \%)$ \\
\hline
\end{tabular}

Table 2: Distribution of respondents by presence of psychiatric health problem by using Goldberg 28 point's general health questionnaire

\begin{tabular}{|c|c|c|}
\hline $\begin{array}{c}\text { Psychiatric health } \\
\text { problem by using } \\
\text { Goldberg 28 } \\
\text { point's GHQ }\end{array}$ & $\begin{array}{c}\text { GHQ } \\
\text { score }\end{array}$ & $\begin{array}{c}\text { Number of } \\
\text { respondents } \\
\text { n(\%) }\end{array}$ \\
\hline Present & $\geq 24$ & $30(57.69 \%)$ \\
\hline Absent & $<2422$ & $(42.31 \%)$ \\
\hline
\end{tabular}


Table 3 : Association of various risk factors with presence of any psychiatric health problem by using GHQ score

\begin{tabular}{|c|c|c|c|c|c|}
\hline \multirow{2}{*}{\multicolumn{2}{|c|}{ Risk factor }} & \multicolumn{2}{|c|}{ Psychiatric health problem } & \multirow{3}{*}{$\begin{array}{c}\text { Total } \\
22\end{array}$} & \multirow{4}{*}{ 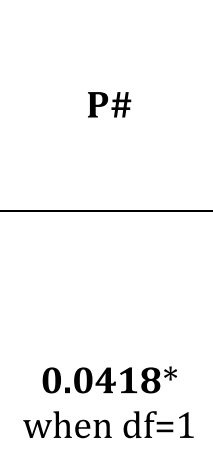 } \\
\hline & & $\begin{array}{c}\text { Present (GHQ } \\
\geq 24)\end{array}$ & Absent (GHQ & & \\
\hline \multirow{3}{*}{$\begin{array}{c}\text { Sexual } \\
\text { identification }\end{array}$} & $\begin{array}{l}\text { Completely } \\
\text { homosexual }\end{array}$ & $\begin{array}{c}13 \\
(59.09 \%)\end{array}$ & $\begin{array}{c}9 \\
(40.91 \%)\end{array}$ & & \\
\hline & Mostly homosexual & $\begin{array}{c}15 \\
(68.18 \%) \\
\end{array}$ & $\begin{array}{c}7 \\
(31.82 \%) \\
\end{array}$ & 22 & \\
\hline & $\begin{array}{c}\text { Sometimes } \\
\text { homosexual }\end{array}$ & $\begin{array}{c}2 \\
(25 \%) \\
\end{array}$ & $\begin{array}{c}6 \\
(75 \%) \\
\end{array}$ & 8 & \\
\hline \multirow{3}{*}{$\begin{array}{c}\text { Sexual } \\
\text { preference }\end{array}$} & Insertive/Active Only & $\begin{array}{c}2 \\
(28.57 \%)\end{array}$ & $\begin{array}{c}5 \\
(71.43 \%)\end{array}$ & 7 & \multirow{2}{*}{$\begin{array}{c}0.4677 \\
\text { when } \mathrm{df}=2 ; \\
0.0936 \\
\text { When df = 1 }\end{array}$} \\
\hline & $\begin{array}{c}\text { Receptive/Passive } \\
\text { Only }\end{array}$ & $\begin{array}{c}9 \\
(56.25 \%)\end{array}$ & $\begin{array}{c}7 \\
(43.75 \%)\end{array}$ & 16 & \\
\hline & $\begin{array}{c}\text { Both Insertive \& } \\
\text { Receptive }\end{array}$ & $\begin{array}{c}19 \\
(65.51 \%)\end{array}$ & $\begin{array}{c}10 \\
(34.49 \%)\end{array}$ & 29 & \\
\hline \multirow{2}{*}{$\begin{array}{l}\text { Number of } \\
\text { sexual } \\
\text { partners }\end{array}$} & $\leq 5$ & $\begin{array}{c}8 \\
(57.15 \%)\end{array}$ & $\begin{array}{c}6 \\
(42.85 \%)\end{array}$ & 14 & \multirow{2}{*}{$\begin{array}{c}0.9611 \\
\text { when } \mathrm{df}=1\end{array}$} \\
\hline & $>5$ & $\begin{array}{c}22 \\
(57.89 \%)\end{array}$ & $\begin{array}{c}16 \\
(42.11 \%) \\
\end{array}$ & 38 & \\
\hline \multirow{2}{*}{$\begin{array}{c}\text { Sex with a } \\
\text { man for } \\
\text { monetary or } \\
\text { other } \\
\text { benefits }\end{array}$} & Yes & $\begin{array}{c}7 \\
(63.64 \%)\end{array}$ & $\begin{array}{c}4 \\
(36.36 \%)\end{array}$ & 11 & \multirow{2}{*}{$\begin{array}{c}0.653 \\
\text { when } \mathrm{df}=1\end{array}$} \\
\hline & No & $\begin{array}{c}23 \\
(56.10 \%)\end{array}$ & $\begin{array}{c}18 \\
(43.90 \%)\end{array}$ & 41 & \\
\hline \multirow{2}{*}{$\begin{array}{c}\text { Marital } \\
\text { Status }\end{array}$} & Yes & $\begin{array}{c}4 \\
(57.14 \%)\end{array}$ & $\begin{array}{c}3 \\
(42.85 \%)\end{array}$ & 7 & \multirow{2}{*}{$\begin{array}{c}0.9747 \\
\text { when } \mathrm{df}=1\end{array}$} \\
\hline & No & $\begin{array}{c}26 \\
(57.77 \%)\end{array}$ & $\begin{array}{c}19 \\
(42.22 \%)\end{array}$ & 45 & \\
\hline \multirow{2}{*}{$\begin{array}{l}\text { Victim or } \\
\text { doer of } \\
\text { Violence } \\
\text { With sex } \\
\text { partners }\end{array}$} & Yes & $\begin{array}{c}15 \\
(88.23 \%) \\
\end{array}$ & $\begin{array}{c}2 \\
(11.77 \%) \\
\end{array}$ & 17 & \multirow{2}{*}{$\begin{array}{c}\text { 0.0019* } \\
\text { when } d f=1\end{array}$} \\
\hline & No & $\begin{array}{c}15 \\
(42.85 \%) \\
\end{array}$ & $\begin{array}{c}20 \\
(57.15 \%)\end{array}$ & 35 & \\
\hline
\end{tabular}

${ }^{\#}$ Chi-square test $*$ Statistically significant 
Table 4: Health seeking behavior in relation to psychiatric health problems among men who have sex with men

\begin{tabular}{|c|c|c|}
\hline \multicolumn{2}{|c|}{ Health care seeking parameters } & $\begin{array}{l}\text { Number of respondents } \\
n(\%)\end{array}$ \\
\hline Treatment received from $(n=21)$ & Doctor (Allopathic) & $12(57.15)$ \\
\hline & Doctor (Ayurvedic) & $0(0.00)$ \\
\hline & Self treatment & $6(28.57)$ \\
\hline & No treatment & $3(14.28)$ \\
\hline \multirow[t]{2}{*}{ Type of health care facility $(n=12)$} & Government & $3(25)$ \\
\hline & Private & $9(75)$ \\
\hline \multirow[t]{5}{*}{ Reasons for preference $(n=12)$} & Better facility & $3(25.00)$ \\
\hline & Cost effective & $3(25.00)$ \\
\hline & $\begin{array}{l}\text { Someone known } \\
\text { recommended }\end{array}$ & $3(25.00)$ \\
\hline & $\begin{array}{l}\text { Trustworthy and well } \\
\text { qualified doctor }\end{array}$ & $2(16.60)$ \\
\hline & Near to residence & $1(8.40)$ \\
\hline \multirow{2}{*}{$\begin{array}{l}\text { Satisfaction with health care } \\
\text { facility }(n=12)\end{array}$} & Satisfied & $9(75.00)$ \\
\hline & Non-Satisfied & $3(25.00)$ \\
\hline \multirow{2}{*}{$\begin{array}{l}\text { Disclosure of sexual behavior to } \\
\text { health care provider }(n=12)\end{array}$} & Yes & $8(66.66)$ \\
\hline & No & $4(33.34)$ \\
\hline $\begin{array}{l}\text { Reason for nondisclosure of } \\
\text { sexual behavior to health care } \\
\text { provider(n=4) }\end{array}$ & $\begin{array}{lr}\text { Fear and stigma } \\
\text { associated } \\
\text { homosexuality }\end{array}$ & $4(100)$ \\
\hline
\end{tabular}

self-reported about presence of any psychiatric health problems during past 1 year while $59.61 \%$ reported not suffering from any psychiatric health problem during past 1 year. (Table1)

Psychiatric health problems by using Goldberg 28 point's general health questionnaire (GHQ) ${ }^{[14]}$ : Goldberg 28 point's general health questionnaire was used as screening procedure to detect respondents suffering from psychiatric illness. Psychiatric morbidity is likely to be present at GHQ threshold score $\geq 24$ out of a maximum possible score of 84 , which was found in $57.69 \%$ of our study population. Rest $42.31 \%$ of respondents had GHQ score less than 24 which translates to absence of any psychiatric health problem among them. (Table 2)

Risk factors for psychiatric health problems: Table 3 shows the association of various risk factors with psychiatric health problems among MSM during the past 1 year. A significantly higher proportion of "completely homosexuals" (MSM who had all their sexual encounters with men) (59.09\%) and "mostly homosexuals" (MSM who had most of their sexual 
encounter with men) (68.18\%) had a psychiatric health problems at the time of interview in comparison to "sometimes homosexuals" (MSM who almost had a proportionate sexual encounter with both males and females $)^{[15-17]}(25 \%)$ When completely and mostly homosexual combined group was compared with sometimes homosexual group, observed differences were found to be statistically significant $(\chi 2=4.1399, \mathrm{df}=1, \mathrm{P}=0.0418)$. It is also observed that majority (88.23\%) of MSM who were victim or doer of violence with sex partners had psychiatric health problems; while among MSM who were not victim/doer of violence with sex partners, only $42.85 \%$ had a psychiatric health problem ever or at the time of interview. These results were found to be statistically significant $\left(\chi^{2}=9.653, \mathrm{df}=1, \mathrm{P}\right.$ $=0.0019$ ). Though MSM who had more than 5 sexual partners, were unmarried, had sex with a man for monetary or other benefits and who played "both active and passive roles" had higher chances of psychiatric health problem during the last 1 year in comparison to their counterparts but this was statistically not significant.

Health seeking behavior : Table 4 shows that the majority $(57.15 \%)$ of respondents sought treatment from an allopathic doctor for their psychiatric health problem. Rest of the respondents either went for a self-treatment $(28.57 \%)$ or had not taken any treatment (14.28\%). The majority (75\%) of MSM opted for a private health facility for their psychiatric health problems. All sought treatment from qualified doctor as reported by respondents. Better facility, cost effectiveness, someone known recommended were the most commonly cited reason among MSM for preferring a particular doctor or health care facility. Reasons like trust worthiness/ well-qualified and near to residence were also mentioned for choosing a particular doctor or health care facility. On being asked about the overall satisfaction with the health care facility where they had received treatment for their psychiatric health problem; only $25 \%$ were reportedly unsatisfied with the health care facility and the most common reason for their dissatisfaction at health facility was bad behavior of staff. Another question which was asked to study participants was: Have you disclosed your sexual behavior to the psychiatric health care provider or not? $66.66 \%$ (8 out of 12 ) of the respondents had reportedly ever disclosed their sexual behavior to his psychiatric health care provider (HCP). When further asked about the reason for not disclosing their sexual behavior to psychiatric HCP, all (4 of them) told that they didn't disclose it out of fear and stigma associated with homosexuality.

\section{Discussion:}

Present study has found that two-fifth (40.4\%) of MSM self-reported about presence of any psychiatric health problem during past one year while according to National Mental Health Survey of India in 2015-16 lifetime prevalence for any mental morbidity among general population was found to be $13.7 \%$. Another report by World health organization has also revealed that $7.5 \%$ of the Indian population suffers from some form of mental disorder. Similarly, studies conducted by Fergusson, et $\mathrm{al}^{[18]}$ in New Zealand, Herrell et $\mathrm{al}^{[18]}$ in Chicago and Sandfort TG et $\mathrm{al}^{[2]}$ in Netherlands has established that prevalence of mental health problems among MSM is much higher than the general population. In India, study by Sivasubramanian $\mathrm{M}$ et $\mathrm{al}^{[1]}$ has also found that gay and bisexual individuals in Mumbai had very high risk of Psychiatric health problems.

Goldberg 28 point's general health questionnaire was used in our study to assess psychiatric health problems among respondents and it was observed that $57.69 \%$ of the MSM have some psychiatric health problem (GHQ $\geq 24$ ). Nearly similar results were found by Deb S et al ${ }^{[19-20]}$ in Kolkata where $63.9 \%$ of the MSM crossed the threshold GHQ score of 24 signaling a high risk of psychiatric illness in this group. On analysis we found that 9 (17.29\%) more individuals were found to have some psychiatric health problem on Goldberg 28 point's general health questionnaire (30 of 52; 57.69\%) in comparison to self-reported mental health problem ( 21 of $52 ; 40.40 \%)$ and this extra yield signifies the role of screening program for assessment of psychiatric health problems among 
men who have sex with men on a regular basis.When an analysis was done to find selected sexual behavior determinants of psychiatric health problems among MSM, it was found that MSM who were either completely or mostly homosexuals and who were victims or doers of violence with sex partner had significantly higher chances of having psychiatric health problem in comparison to their respective counterparts and these results were statistically significant. The current study also found that prevalence of psychiatric health problems (GHQ score $\geq 24$ ) was almost equal among married and unmarried MSM (57.14\% v/s 57.77\%) however, the observed difference was not statistically significant.

The present study has found that only $57.15 \%$ of MSM took treatment for their mental health problem while rest $42.85 \%$ took no treatment from any health professional among which two third $(28.57 \%)$ went for self treatment while one third (14.28\%) absolutely sought no treatment. This shows that treatment seeking behavior for mental health problem is quite poor. This also reflects that many MSM don't take their mental health seriously or hesitate to discuss their mental health issues at health facility probably due to fear of stigma and discrimination associated with it. Another probable reason for poor mental health seeking behavior may be due to scarcity of mental health experts as well as sub-optimal utilization of available mental health services in India and this issue among MSMs need to be re-addressed. Present study has also found that none of the participant took treatment for their mental health problem from an Ayurvedic doctor.

In the present study, only one-fourth reportedly had taken treatment from a government health facility; so it seems that either the MSM don't have trust in available government psychiatric health facilities or there may be geographic or cultural inaccessibility at government psychiatric health facilities for MSM. In the present study all those respondents who sought treatment for a psychiatric health problem, all were reportedly treated by a qualified doctor. Better facility, cost effectiveness, someone known recommended were the most common cited reason for preferring a particular doctor/health facility for their psychiatric health problems. It was not surprising to found that, no MSM preferred his family doctor for treatment of their mental health problem probably due the fear of disclosing his sexual orientation/behavior with his closed one and other family members.

In the present study $75 \%$ respondents said that they were satisfied by the treatment for their psychiatric health problem which they received at that health care facility. One-fourth of them were dissatisfied with the treatment they received. Most common reason for dissatisfaction was bad behavior of staff. Probable reasons for such high level of dissatisfaction with mental health care facility might be due to long duration of treatment or due to lack of sufficient time by the doctor due to overcrowding and limited number of mental health experts at the health care facility.

Rate of disclosure at a mental health facilities was found to be high, probably due to the fact that they were more talkative and uninhibited due to their psychiatric health illness and so they got overwhelmed and discussed about their sexuality and sexual behavior more frequently and comfortably while in physical and sexual health facilities they just got symptomatic treatment most of the time keeping in view that heteronormativity solely exists.20 Four out of twelve MSM who had not disclosed about their sexual behavior to their psychiatric health care provider narrated that they (all 4) didn't disclosed it out of fear and stigma associated with homosexuality.

\section{Conclusion:}

This study highlights that's significant proportion of MSM population had suffered from psychiatric health problems. Application of psychiatric screening test in the form of Goldberg GHQ-28 helped in identifying hidden undiagnosed or asymptomatic psychiatric cases among them. Health- seeking behavior of MSM community was quite unsatisfactory. The high rate of psychiatric health issues and gaps in treatment seeking behavior indicated an urgent need to increase mental health awareness among MSM population. 


\section{Recommendation:}

MSM community requires geographic, economic as well as cultural accessibility to mental health screening programs, psychiatric counseling and behaviour therapy through trained mental health care professionals. The high rate of psychiatric health issues and gaps in treatment seeking behavior indicates an urgent need to increase mental health awareness among MSM population. As many MSMs fears disclosing their sexual behavior, telephonic psychiatric counseling even at government mental health facilities can be beneficial. Training of medical and para-medical professionals about psycho-sexual health issues of MSM is needed to improve the mental health care of MSM.

\section{Limitation of study:}

Confounding factors, as family history of mental disorder, broken family, orphan, alcohol or substance use, financial conditions, other stress factors prone to cause mental illness may need to be studied. A small sample size for close end questions is also the limitation of the study.

\section{Declaration:}

Funding: Nil

Conflict of Interest: Nil

\section{References:}

1. Sivasubramanian M, Mimiaga MJ, Mayer KH, Anand VR, Johnson $\mathrm{CV}$, Safren SA. Suicidally, clinical depression, and anxiety disorders are highly prevalent in men who have sex with men in Mumbai, India: findings from a community recruited sample. Psychol Health Med. 2011; 16(4): 450-462. pmid:21749242

2. Sandfort TG, Bakker F, Schellevis FG, Vanwesenbeeck I. Sexual orientation and mental and physical health status: findings from a Dutch population survey. Am J Public Health 2006; 96(6): 1119-1125. pmid:16670235.

3. Asch SM, et al. Underdiagnosis of depression in HIV. J Gen Intern Med. $2003 ; 18: 450-60$. doi: $10.1046 / j .1525$ 1497.2003.20938.x.

4. Cochran SD, Mays VM. Burden of psychiatric morbidity among lesbian, gay, and bisexual individuals in the California Quality of Life Survey. J Abnorm Psychol. 2009;118:647-58. doi: $10.1037 / \mathrm{a} 0016501$.

5. King M, etal. A systematic review of mental disorder, suicide, and deliberate self harm in lesbian, gay and bisexual people. BMC Psychiatry. 2008;8:70. doi: 10.1186/1471-244X-8-70.

6. O'Cleirigh C, Magidson JF, Skeer MR, Mayer KH, Safren SA. Prevalence of psychiatric and substance abuse symptomatology among HIV-infected gay and bisexual men in HIV primary care. Psychosomatics. 2015;56:470-8. doi: 10.1016/j.psym. 2014.08.004.

7. Mills TC, et al. Distress and depression in men who have sex with men: the Urban Men's Health Study. Am J Psychiatry. 2004;161:278-85. doi: 10.1176/appi.ajp.161.2.278.

8. Roberts AL, Austin SB, Corliss HL, Vandermorris AK, Koenen KC. Pervasive trauma exposure among US sexual orientation minority adults and risk of posttraumatic stress disorder. Am J Public Health. 2010;100:2433-41. doi: 10.2105/AJPH. 2009.168971.

9. McCabe SE, Hughes T, Bostwick WB, West BT, Boyd CJ. Sexual orientation, substance use behaviors and substance dependence in the United States. Addiction. 2009;8:1333-45. doi: 10.1111/j.1360-0443.2009.02596.

10. Chen G, Li Y, Zhang B, Yu Z, Li X, Wang L, et al. Psychological characteristics in high-risk MSM in China. BMC Public Health. 2012; 12:58. pmid:22264355

11. Jie W, Ciyong L, Xueqing D, Hui W, Lingyao H. A syndemic of psychosocial problems places the MSM (men who have sex with men) population at greater risk of HIV infection. PLoS One. 2012; 7: e32312.pmid:22479319

12. Bouhnik AD, Préau M, Schiltz MA, Peretti-Watel P, Obadia Y, Lert F, et al. Unsafe sex with casual partners and quality of life among HIV-infected gay men: evidence from a large representative sample of outpatients attending French hospitals (ANRS-EN12VESPA). Acquir Immune DeficSyndr. 2006; 42: 597-603.

13. Li D, Li C, Wang Z, Lau JT. Prevalence and associated factors of unprotected anal intercourse with regular male sex partners among HIV negative men who have sex with men in China: a cross-sectional survey. PLoS One. 2015; 10(3): e0119977. pmid:25816292

14. Herrell R, Goldberg J, True WR, Ramakrishnan V, Lyons M, Eisen S, Tsuang MT. Sexual orientation and suicidality: A co-twin control study in adult men. Arch Gen Psychiatry1999;56:867-874.

15. Berlan ED, Corliss HL, Field AE, Goodman E, Austin SB. Sexual orientation and bullying among adolescents in the growing up today study.J Adolesc Health2010;46:366-71.

16. Saewyc EM, Bearinger LH, Heinz PA, Blum RW, Resnick MD. Gender differences in health and risk behaviors among bisexual and homosexual adolescents.J Adolesc Health1998;23:181-8.

17. Kinsey AC, Pomeroy WR, Martin CE. Sexual behavior in the human male. 1948.Am J Public Health2003;93:894-8.

18. Fergusson DM, Horwood LJ, Beautrais AL. Is sexual orientation related to mental health problems and suicidality in young people? Arch Gen Psychiatry1999;56:876-880.

19. Deb S, Dutta S, Dasgupta A, Roy S.Hidden Psychiatric Morbidities and Physical Health Status Among Men Who have Sex with Men and Other Clients of a Sexually Transmitted Disease Clinic of Kolkata: A Comparative Study.IJCM 2010;35(1):193-197

20. Meyer IH. Prejudice, social stress, and mental health in lesbian, gay, and bisexual populations: conceptual issues and research evidence. Psychological bulletin. 2003 Sep;129(5):674. 